\title{
Retromolar tracheal intubation in a pediatric patient with a difficult airway and bilateral nasal stenoses
}

\author{
Angela Truong, MD $\cdot$ Dam-Thuy Truong, MD
}

Received: 20 March 2012/Accepted: 17 April 2012/Published online: 27 April 2012

(c) Canadian Anesthesiologists' Society 2012

\section{To the Editor,}

As the number of unsuccessful attempts increases in cases of difficult tracheal intubation, the incidence of airway trauma and risk of obstruction also increase. We present the case of a pediatric patient with a difficult airway scheduled for mandibulectomy. Tracheal intubation attempts using conventional techniques were unsuccessful. To overcome this challenge, the retromolar approach was used to achieve successful fibreoptic orotracheal intubation. Written consent was obtained from the patient's mother for publication of this report including the two related images.

An eight-year-old boy (weight $21 \mathrm{~kg}$, height $125 \mathrm{~cm}$ ) with mandibular rhabdomyosarcoma presented for right segmental mandibulectomy. At the age of two, he underwent tumour resection and reconstructive plastic surgery with a scapular osteocutaneous flap followed by radiation therapy. Subsequent overgrowth of the bone flap resulted in mandibular asymmetry with malocclusion. His chin deviated to the left with a prognathic mandible, and limited right temporomandibular joint mobility caused severe trismus. The maximal interincisor distance measured $8 \mathrm{~mm}$, and his airway was assessed as Mallampati class 4 (Fig. 1).

General anesthesia was induced with propofol $40 \mathrm{mg} i \mathrm{v}$ given in incremental doses. After ensuring adequate ventilation of the patient's lungs by bag and mask, fentanyl $30 \mu \mathrm{g}$ and rocuronium $10 \mathrm{mg} i v$ were given. Planned oral fibreoptic intubation using a pediatric bronchoscope was unsuccessful. Nasal fibreoptic intubation was attempted

A. Truong, MD $(\bowtie) \cdot$ D.-T. Truong, MD

The University of Texas MD Anderson Cancer Center, Houston, TX, USA

e-mail: atruong@mdanderson.org next, but resistance was encountered when the pediatric bronchoscope was inserted through both right and left nares. A small amount of bleeding, which resulted from insertion of the bronchoscope, was suctioned from the oropharynx. The bronchoscope was then inserted into the left retromolar space. The epiglottis and glottis were identified, and a 5.0-mm internal diameter tracheal tube was guided over the bronchoscope through the vocal cords for successful tracheal intubation (Fig. 2). After uneventful surgery, the trachea was extubated and the patient was transferred to the postanesthesia care unit in good condition.

In a previous report, we described the use of the retromolar space as a point of access for tracheal intubation in an adult patient who presented with an interincisor distance insufficient to allow passage of the endotracheal tube. ${ }^{1}$ The retromolar space has been used for tracheal intubation in children with Pierre Robin malformation as an alternative to the unsuccessful classical method. ${ }^{2}$ This report describes an indication for use of the retromolar space in a pediatric patient using a flexible fibrescope. In this case, even though the mouth opening allowed passage of an endotracheal tube of appropriate size, repeated attempts at fibreoptic tracheal intubation between the teeth were unsuccessful. A combination of restricted mouth opening from temporomandibular joint immobility, airway distortion secondary to severe mandibular asymmetry, and the presence of a large tongue and full set of teeth contributed to make tracheal intubation attempts using traditional approaches unsuccessful. Furthermore, the usual maneuvers to relieve soft tissue obstruction, such as chin lift and jaw thrust, were ineffective to expose the glottic opening. An awake fibreoptic tracheal intubation was not chosen due to the patient's young age and inability to cooperate and an anticipated difficulty in airway topicalization. ${ }^{3}$ An inhalational induction was not selected 


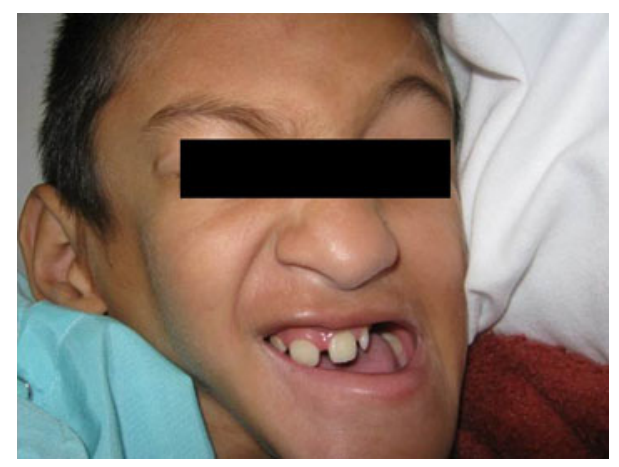

Fig. 1 Airway assessment with maximal mouth opening

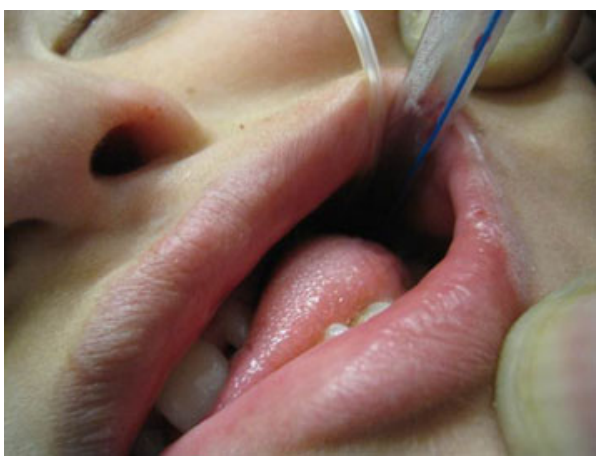

Fig. 2 Successful left retromolar tracheal intubation

due to the patient's strong objection, and severe trismus precluded the intraoral insertion of a rigid laryngoscope. When unexpected bilateral nasal stenoses were encountered and epistaxis resulted from attempts to insert the bronchoscope, this route was quickly abandoned. Fibreoptic tracheal intubation using the retromolar space was performed. Located between the last molar and the ascending ramus of the mandible, the retromolar space has been used to anchor tracheal tubes after maxillofacial surgery in children. ${ }^{4}$ In this case, by bypassing the intraoral obstacles of tongue and teeth in a patient with limited mouth opening, the retromolar space offered a direct and more manageable unobstructed path to the glottis. Flexible fibreoptic retromolar tracheal intubation in a pediatric patient provided a valuable option to manage the challenge of a difficult airway.

Disclosures No funding sources (departmental, hospital, institutional, or commercial) were used in our submitted work. We have no affiliations, commercial or non-commercial, that may be perceived to be a conflict of interest with our work. We have no other associations, such as consultancies, to disclose.

\section{References}

1. Truong A, Truong DT. Retromolar fibreoptic orotracheal intubation in a patient with severe trismus undergoing nasal surgery. Can J Anesth 2011; 58: 460-3.

2. Bonfils $P$. Difficult intubation in Pierre-Robin children, a new method: the retromolar route (German). Anaesthesist 1983; 32: 363-7.

3. Xиe FS, Luo MP, Xи YC, Liao X. Airway anesthesia for awake fiberoptic intubation in management of pediatric difficult airways. Paediatr Anaesth 2008; 18: 1264-5.

4. Arora S, Rattan V, Bhardwaj N. An evaluation of the retromolar space for oral tracheal tube placement for maxillofacial surgery in children. Anesth Analg 2006; 103: 1122-5. 